\title{
Effects of different types of smoking cessation behavioral therapy in disadvantaged areas in the Netherlands: an observational study
}

Fiona Benson ${ }^{1}$, Vera Nierkens ${ }^{2}$, Marc C Willemsen ${ }^{3}$, Karien Stronks ${ }^{1}$

\begin{abstract}
BACKGROUND Smokers in disadvantaged areas smoke more and make less successful quit attempts than smokers in other areas. Smoking cessation behavioural therapy (SCBT) +/- pharmacotherapy, can increase quit success, however, several different types of counselling are available. Settings also differ. The type of counselling which best assists smokers in disadvantaged areas to quit is unknown. We investigated the effect of four different types of SCBT offered in disadvantaged areas of the Netherlands (individual face-to-face, telephone, rolling group and fixed group counselling), and explored differences of effect between intervention types.

METHODS Data from 415 participants were collected from Dutch SCBT programmes serving disadvantaged areas. Settings included hospital, community, and primary care. Data collection included repeated survey and medical record research. Participants' self-reported and CO-validated continuous abstinence prevalence per intervention type initially, and at 6 and 12 months were calculated. Predictors of continuous cessation at 12 months were analysed using logistic regression analysis.

RESULTS Overall, 19\% of participants were of low educational level. There was a $30 \%$ overall selfreported continuous abstinence prevalence at 12 months, which was highest in rolling group counselling (41\%) and individual face-to-face counselling (35\%). Fixed group counselling in hospital setting was more effective than in other settings. Both group counselling types were equally effective in a hospital setting.

CONCLUSION Group counselling in a hospital setting is the most successful type of intervention in supporting smokers in disadvantaged areas to quit. We recommend that services in disadvantaged areas concentrate on offering group counselling, given in a hospital setting, where possible.
\end{abstract}

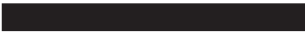 \\ AFFILIATION \\ 1 Academic Medical Centre \\ - University of Amsterdam, \\ Netherlands \\ 2 Leiden University Medical \\ Center (LUMC), \\ Netherlands \\ 3 Maastricht University, \\ Netherlands
}

CORRESPONDENCE TO

Fiona Benson. Academic

Medical Centre -

University of Amsterdam,

Meibergdreef 9, $1105 \mathrm{AZ}$

Amsterdam, Netherlands

Email: f.e.benson@amc.

uva.nl

\section{KEY WORDS}

Smoking cessation,

Socioeconomic status,

Behavioral therapy,

Disadvantaged

Neighborhood

Netherlands

\section{INTRODUCTION}

Tobacco is a risk factor for six of the eight leading causes of death worldwide and is responsible for one in every ten adult deaths worldwide ${ }^{1}$. In high income countries, those living in disadvantaged areas smoke more ${ }^{2-4}$ and make less successful quit attempts, ${ }^{5,6}$ than those living in the most advantaged areas. Intensive smoking cessation behavioural therapy (SCBT), with or without pharmacotherapy, can increase the chance of a successful quit attempt ${ }^{7-10}$. However, there are many types of intensive SCBT available, including courses of individual faceto-face, telephone, rolling group or fixed group counselling.

Each type of SCBT has advantages and disadvantages. Group counselling, provided to a group of smokers by a trained smoking cessation counsellor, provides the opportunity for participants to experience group support and social learning ${ }^{8,9}$ but can also possibly lead to demotivation due to unhelpful group processes (e.g. rivalry, envy, fear of failure/loss of face $)^{8,11,12}$. Group counselling can be provided in a fixed group or rolling group format. In fixed (closed) group counselling, a group is assembled and no new participants enter the group once the counselling has started. Often the start date of the course is set once a minimum group number has been reached. This has the advantage of the group being able to develop a strong social support network as they see each other regularly. However, it can mean waiting to start ${ }^{13}$ and, if there is a high level of drop-out, participants may feel demotivated as the group gets smaller ${ }^{11}$. Rolling group counselling (also called open group), involves the continuous sequential repetition of sessions throughout the year. This enables participants to stream in and out at any time, so they can start straight away ${ }^{13}$ and there is a chance to catch up on any session they miss because the sessions are repeated regularly. The regular change of participants may enable newcomers to learn from the experiences of experienced participants ${ }^{13}$ however, it could also prevent the development of 
a strong mutual support network.

Individual counselling, either face-to-face or by telephone is provided to smokers on an individual basis by trained smoking cessation counsellors ${ }^{10,14}$. Individual counselling provides the opportunity for tailoring to the patients individual needs (i.e. free-choice topics can be selected by the participant based on their needs) ${ }^{14}$ while also covering the general course material. However, it does not provide the group benefits, as mentioned previously. While both individual forms are more flexible than group counselling, allowing appointments to be scheduled when suitable for the participant, telephone counselling is very flexible, as a participant does not have to be present in a certain place at a certain time ${ }^{15}$ and can possibly reschedule appointments at short notice ${ }^{11}$. This may be suited to people who find it difficult to attend set appointments in person, such as mothers with little support or people with busy or irregular jobs ${ }^{11}$. However, some smokers may be suspicious about the confidentiality of such a service or may not be able to envision themselves being helped over the telephone ${ }^{15}$.

It is possible that different intervention types may differ in their effectiveness. In the UK, group counselling has been found to be more effective than individual counselling ${ }^{16,17}$. However, type of group counselling is also of importance, with one UK study finding that the best results overall and in those of low socioeconomic status (SES) could be found in rolling (open) group counselling in comparison with one-to-one, drop-in clinic, and fixed group counselling ${ }^{18}$. No significant effect of area disadvantage on quitting was found in this UK study ${ }^{18}$.

In addition, SCBT may be delivered in a range of different physical settings, including primary care ${ }^{19,20}$, pharmacy ${ }^{21}$, community $^{20}$ or hospital settings ${ }^{22}$. Differences in success of SCBT by setting has been found in the UK, where specialist clinics were found to be more effective than therapy provided in other settings, such as primary care or pharmacy settings ${ }^{17}$. However, the actual physical location of these specialist clinics was not indicated ${ }^{17}$.

The aim of this paper is to examine the effects of four different types of SCBT offered in disadvantaged areas of the Netherlands. In the Netherlands, one course of intensive SCBT per smoker (with or without pharmacotherapy) is reimbursed each year in the basic health insurance package. Evidencebased intensive behavioural therapy can be delivered in several formats, including the aforementioned individual "and group counselling types," and in different settings ${ }^{23}$. We will examine 12 month continuous abstinence status by type of SCBT intervention (individual face-to-face, telephone, fixed group or rolling group counselling) and explore the differences between different types of counselling in different settings.

\section{METHODS}

\section{Participants \& counselling type}

Data from 415 participants of $\geq 18$ years of age, who had commenced SCBT, were collected from four smoking cessation services located in urban areas of the Netherlands (Figure 1). Two of these services, located in disadvantaged areas ${ }^{24}$ were offered in primary care (Service A) and community settings (Service B). Further information on the recruitment of these participants and the sites involved can be found in Benson et al. ${ }^{25}$. The other two services (Services C \& D), with catchment areas including disadvantaged areas, were specialist smoking cessation clinics in hospital settings. Examples of these setting types can also be found in other areas of the Netherlands ${ }^{26}$. Information about the intervention offered at each service can be viewed in Tables $1 \& 2$.

All counsellors had received training in smoking cessation counselling. Group courses had 8-15 participants. The course structure of group counselling varied between Services A,B \& C, who offered a standard fixed group counselling course ${ }^{12}$ and Service D, which offered a course whereby participants must first read a book or listen to a CD about smoking cessation, ${ }^{27,28}$ followed by filling in a step-by-step plan, finalising the plan and then choosing group or individual counselling.

Despite this, all interventions used similar content, including self-analysis, analysis of tempting situations/pitfalls, behavioural change, rewards, cravings, dealing with social pressure and relapse prevention.

Pharmacotherapy was discussed with all participants at all services early in the counselling, except for Telephone counselling at Service A, where it was only discussed with those smoking $>10$ cigarettes per day. Some services provided participants with prescriptions for pharmacotherapy, while participants of others needed to organise the pharmacotherapy themselves (Tables $1 \& 2$ ).

Data from Services A \& B were gained from repeated cross-sectional surveys. The surveys were taken at baseline (pre-intervention), and then 4-6 weeks, 6 months and 12 months after their agreed quit date. Informed consent was gained from all participants at these two sites. Further details can be seen at Benson et al., ${ }^{25}$. CO-validation was done at sites A \& B by interviewers using a Bedfont piCO+ Smokerlyzer device. $\mathrm{CO}$ readings were taken during interviews by trained interviewers. Data from services C \& D were gained through patient medical records, where all participants from the smoking cessation clinics who had been referred by the General Practitioner (GP) were included.

This was supplemented by follow-up data provided by the 
services. Under Dutch law, medical ethical approval is not required for scientific research which does not undertake an intervention $^{29}$. Recruitment took place from May 2011October 2013.

\section{Variables \& Analysis}

\section{Socioeconomic status (SES)}

Highest education level attained was used as a proxy for $\mathrm{SES}^{30}$. The following categories were used:no/primary/lower secondary education was considered low SES, mid/upper secondary education was considered middle SES, and tertiary education was considered high SES. This information was missing for approximately one third of participants in service $\mathrm{C}$ and two thirds in service D.

\section{Average cigarettes perday}

Average cigarettes per day was used as a proxy for nicotine dependence ${ }^{31}$.

\section{Quit status - Self-reported}

Self-reported continuous abstinence status was measured at 3 moments: initial, 6 and 12 months. For two of the services (C\&D), self-reported follow-up was gained by phoning participants, and asking whether they had stopped smoking.
For the other two services $(A \& B)$, quit status was determined through questions from the interviewer-led questionnaire. At 4-6 weeks participants were asked: "Have you smoked in the last 14 days, even if it was just one cigarette or self-rolled cigarette or only one puff?" This allowed for a 2 week grace period. ${ }^{32}$. And at 6 and 12 months: "Have you smoked since your agreed quit date, even if it was only one cigarette or selfrolled cigarette or only one puff?" Those smoking 0-5 cigarettes in the entire period were considered non-smokers, while those smoking $>5$ cigarettes were considered smokers ${ }^{32}$. Participants were categorised as smoking, quit or unknown for each measure.

The timing of the initial measurement after the agreed quit date differed between services. Service C followed up immediately, Services A \& B at 4-6 weeks, and Service D at 3 months.

Self-reported continuous abstinence status was calculated such that participants who reported that they were smoking at a follow-up (Service C\&D) or they had smoked $>5$ cigarettes in the entire period (Service A\&B), were considered to be smokers for that period and the rest of the follow-up period. Participants who missed a follow-up at 3 or 6 months were considered to be unknown for that follow-up (neither smoker or non-smoker and remaining in the denominator). If at a

Table 1: Description of the group counselling offered by each service.

$\begin{array}{lllc} & \text { Service I } & \text { Service B } & \text { Service C } \\ \text { Setting } & \text { Primary care } & \text { Community } & \text { Hospital } \\ \text { Language offered } & \text { Dutch \& Turkish } & \text { Dutch } & \text { Dutch \& English } \\ \text { Intervention type } & \text { Fixed } & \text { Fixed } & \text { Fixed }\end{array}$

Number of sessions of 1.5-2 hours duration.

$\begin{array}{ll}\begin{array}{l}\text { Timing of official stop } \\ \text { date }\end{array} & \text { Session } 4 \\ \begin{array}{l}\text { Permitted to keep } \\ \text { participating if not } \\ \text { stopped on official stop } \\ \text { date }\end{array} & \text { Yes } \\ \begin{array}{l}\text { Pharmacotherapy } \\ \text { Topic is discussed early } \\ \text { in the counselling. } \\ \text { Prescriptions are provided } \\ \text { to participants who wish to } \\ \text { use it. Prescriptions must } \\ \text { be filled by the participants } \\ \text { themselves. }\end{array}\end{array}$

Some courses had 2

additional sessions on lifestyle topics chosen by the participants (e.9. stress management).
9 standard weekly sessions. 9 standard weekly sessions.

Between session 3-4.

Yes

Topic is discussed in the first session. Information on pharmacotherapy is also available in the course material. Participants must organise pharmacotherapy themselves.
Approximately 14 sessions spread over 12 months, with the first seven sessions in the first four months.

Between sessions 3-4

Yes

Topic is discussed with participants in second session. Participants advised to use pharmacotherapy and, if they choose to do so, the prescription is provided. Prescriptions must be filled by the participants themselves.
2-3 individual sessions with the smoking cessation counsellor and then 7 group sessions.

Between session 1-2

No

Topic is discussed in the pre-reading (book/CD) and with the counsellor early in the counselling. Participants must organise pharmacotherapy themselves. 
subsequent follow-up they were found to be 'abstinent', they were considered to be abstinent for the entire period, at that time point. Participants who missed the 12 month follow-up were considered to be smokers for the entire period ${ }^{32}$.

\section{Quit status - CO-validated}

At two of the services (A\&B), CO-validation of self-reported continuous abstinence status was done. A participant was considered $\mathrm{CO}$-validated quit if they had smoked $<5$ cigarettes for the entire period and their $\mathrm{CO}$-meter reading was .9ppm, which is the standard cut-off ${ }^{32}$.

\section{Pharmacotherapy}

Participants who used pharmacotherapy were coded as having used pharmacotherapy if they had used either varenicline, bupropion or nicotine replacement (patches, lozenges, chewing gum or nasal spray).

\section{Attendance}

When attended completely, all interventions consist of $\geq 7$ sessions. Attendance was dichotomised as intensive (at least 4 sessions of at least 40 minutes duration in total) and nonintensive (less than 4 sessions and/or less than 40 minutes in total) according to the Dutch Guideline for Treatment of Tobacco Addiction $^{33}$.

\section{Statistical Analysis}

Statistical analysis was performed using IBM SPSS Statistics, Version 21 (Release 21.0.0.1). Differences between participant characteristics between counselling types were tested using Pearson's Chi Square test and one-way ANOVA, excluding missing values. Self-reported and $\mathrm{CO}$-validated continuous abstinence prevalence per intervention type was calculated using: successful quitters/total participants. Univariate logistic regression analysis was used to explorer whether 12 month selfreported continuous abstinence prevalences differed per intervention type, taking into account setting characteristics and controlling for confounders. Confounders included age ${ }^{16,18}$ gender, ${ }^{34} \mathrm{SES}^{16,18}$ average cigarettes per day ${ }^{35}$ pharmacotherapy use $^{17}$ and attendance ${ }^{36}$. Variables with a $p$-value of .0 .2 in a univariate model and which changed the Odds Ratio of quitting for a specific intervention type by $>10 \%$ were included in a multivariate logistic regression analysis. To prevent loss of data due to complete case analysis, in variables with large amounts of missing data, such as educational level, those with missing data were put into a separate category.

\section{RESULTS}

The characteristics of participants differed between intervention types (Table 3). There was a significant difference in educational level $(p=0.00)$. Fixed group and telephone counselling had

Table 2: Description of the individual counselling offered by each service.

\begin{tabular}{|c|c|c|c|}
\hline & Service A & Service C & Service D \\
\hline Setting & Primary care & Hospital & Hospital \\
\hline Language offered & Dutch \& Turkish & Dutch \& English & Dutch \\
\hline Intervention type & Telephone & Face-to-face & Face-to-face \\
\hline $\begin{array}{l}\text { Number of sessions } \\
\text { and course duration }\end{array}$ & $\begin{array}{l}7 \text { standard sessions over } 3-4 \text { months with } \\
\text { up to } 5 \text { extra sessions if relapse occurs or } \\
\text { the participant has not stopped after the first } \\
\text { session. }\end{array}$ & $\begin{array}{l}\text { Approx. } 16 \text { sessions over } 12 \text { months, } \\
\text { with two extra sessions in the } \\
\text { second year if the participant is still } \\
\text { abstinent and feels the sessions are } \\
\text { necessary. }\end{array}$ & $\begin{array}{l}\text { 7-8 sessions with the smoking } \\
\text { cessation counsellor over } 12 \text { months, } \\
6 \text { of which occur in the first } 4 \text { months } \\
\text { of that year. }\end{array}$ \\
\hline $\begin{array}{l}\text { Timing of official } \\
\text { stop date }\end{array}$ & Between sessions 1-2 & After sessions 2 or 3 . & Between sessions 1-2. \\
\hline $\begin{array}{l}\text { Permitted to keep } \\
\text { participating if not } \\
\text { stopped on official } \\
\text { stop date }\end{array}$ & Yes & Yes & $\begin{array}{l}\text { Yes, but if the agreed stop date } \\
\text { is missed approximately twice } \\
\text { participants must have a time-out. }\end{array}$ \\
\hline $\begin{array}{l}\text { Permitted to } \\
\text { continue if relapse }\end{array}$ & Yes & Yes & $\begin{array}{l}\text { Yes, but after approx. } 2 \text { relapses they } \\
\text { must have a time-out of minimum } 3 \\
\text { months. }\end{array}$ \\
\hline Session duration & $\begin{array}{l}\text { Session 1: } 30 \text { minutes (mins). } \\
\text { Subsequent sessions: } 15 \text { mins. }\end{array}$ & $\begin{array}{l}\text { Session 1: } 1 \text { hour. Subsequent } \\
\text { sessions: } 30 \text { mins. }\end{array}$ & $\begin{array}{l}\text { Session 1: } 40 \text { mins. Subsequent } \\
\text { sessions: } 20 \text { mins. }\end{array}$ \\
\hline Pharmacotherapy & $\begin{array}{l}\text { Topic is discussed early in the counselling } \\
\text { with participants smoking }>10 \text { cigarettes } \\
\text { per day. The participant must organise } \\
\text { this themselves. Forms were provided } \\
\text { (excluding 2012) to help participants gain } \\
\text { reimbursement for medication costs. }\end{array}$ & As per group therapy at this service. & As per group therapy at this service. \\
\hline
\end{tabular}


the highest proportions of participants with low educational level (both 40\%). Individual face-to-face counselling had the highest proportion of highly educated participants (26\%).

Gender was approximately evenly split in the total group, with the highest percentage of female participants being in the telephone counselling group $(\geq 58 \%)$. There was a significant difference in pharmacotherapy use $(p=0.00)$. Pharmacotherapy use in telephone counselling (45\%) was lower than in other intervention types (53\%). There was a significant difference in attendance between intervention types ( $p=0.00$ ), with telephone and rolling group counselling having lower attendances (Means of 2.9 and 5.0 respectively) than the other intervention types (Means of $\geq 6.8$ ). Average cigarettes per day were very similar amongst all intervention types. There was a large amount of missing data on educational level (33\%), marital status (45\%) and pharmacotherapy use (22\%).

Table 4 shows the self-reported and CO-validated continuous abstinence prevalences, both overall and per intervention type. Overall, the self-reported continuous abstinence prevalence at 12 months was $29.9 \%$. The self-reported continuous abstinence prevalence at 12 months was highest for rolling group (41\%) and individual face-to-face counselling (34.7\%). Lower self-reported 12 month continuous abstinence prevalences were reported for fixed group (15.4\%) and telephone counselling (7.9\%). Twelve month $\mathrm{CO}$-validated continuous abstinence prevalences were lower than the self-reported prevalences, namely $6.4 \%$ overall, $7.0 \%$ for fixed group and $5.3 \%$ for telephone counselling respectively. In the participants as a group, approximately a third of participants dropped out (Table 4). Drop-out differed per intervention type, with the highest experienced in telephone counselling (66\%) and the lowest in rolling group counselling $(12 \%)$.

After controlling for individual and intervention characteristics, we found that telephone and fixed group

Table 3: Participant characteristics, overall and per counselling type.

\begin{tabular}{|c|c|c|c|c|c|c|c|}
\hline Charncteristics & & $\begin{array}{l}\mathrm{A} / I \\
(\mathrm{n}=415)\end{array}$ & $\begin{array}{l}\text { Individual face } \\
\text { to face }(n-216)\end{array}$ & $\begin{array}{l}\text { Telephone } \\
\text { (n -38) }\end{array}$ & $\begin{array}{l}\text { Fixed group } \\
(n=78)\end{array}$ & $\begin{array}{l}\text { Rolling } \\
\text { group } \\
(n=83)\end{array}$ & $\begin{array}{l}p \text {-value comparing } \\
\text { counselling types }\end{array}$ \\
\hline & $n(\%)$ & & & & & & \\
\hline \multirow[t]{2}{*}{ Gender } & Male & $198(48)$ & $99(46)$ & $16(42)$ & $45(58)$ & $38(46)$ & $0.27^{*}$ \\
\hline & Female & $215(52)$ & $115(53)$ & $22(58)$ & $33(42)$ & $45(54)$ & \\
\hline \multirow[t]{4}{*}{ Educational status } & Low & $79(19)$ & $28(13)$ & $15(40)$ & $31(40)$ & $5(6)$ & $0.00^{*}$ \\
\hline & Middle & $120(29)$ & $54(25)$ & $19(50)$ & $31(40)$ & $16(19)$ & \\
\hline & High & $80(19)$ & $55(26)$ & $4(11)$ & $15(19)$ & $6(7)$ & \\
\hline & Missing & $136(33)$ & $79(37)$ & - & - & $56(68)$ & \\
\hline \multirow[t]{3}{*}{ Marital status } & $\begin{array}{l}\text { No } \\
\text { Partner }\end{array}$ & $100(24)$ & $42(19)$ & $20(53)$ & $38(49)$ & & $0.44^{*}$ \\
\hline & Partner & $87(21)$ & $29(13)$ & $18(47)$ & $40(51)$ & & \\
\hline & Missing & $228(45)$ & $145(67)$ & - & - & & \\
\hline \multirow[t]{4}{*}{ Pharmacotherapy } & Yes & $245(59)$ & $137(63)$ & $17(45)$ & $47(60)$ & $44(53)$ & $0.00^{*}$ \\
\hline & No & $79(19)$ & $25(12)$ & $7(18)$ & $16(21)$ & $31(37)$ & \\
\hline & Missing & $91(22)$ & $54(25)$ & $14(37)$ & $15(19)$ & $8(10)$ & \\
\hline & \multicolumn{7}{|c|}{ Mean(SD) } \\
\hline $\begin{array}{l}\text { Age (years) } \\
(n=408)\end{array}$ & & $49.5(11.7)$ & $49.4(11.1)$ & $45.5(12.9)$ & $49.4(13.2)$ & $51.8(10.7)$ & $0.54^{* *}$ \\
\hline $\begin{array}{l}\text { Cigarettes per day } \\
(n=379)\end{array}$ & & $21.7(10.1)$ & $21.3(9.2)$ & $22.3(11.8)$ & $23.4(12.2)$ & $20.6(8.7)$ & $0.31^{* *}$ \\
\hline $\begin{array}{l}\text { Sessions attended } \\
(n=368)\end{array}$ & & $6.2(5.0)$ & $6.8(5.9)$ & $2.91(1.4)$ & $6.9(3.8)$ & $5.0(2.9)$ & $0.00^{* *}$ \\
\hline
\end{tabular}


counselling were significantly less effective than the reference group individual face-to-face counselling (Odds Ratio (OR): telephone counselling $0.18[0.05-0.66] p$-value $=0.01$ and fixed group 0.31 [0.15-0.63] $p$-value $=0.00)$ ) (Table 5). Rolling group counselling had a tendency to be more effective, though did not differ significantly, from individual face-to-face counselling (OR:1.62[0.92-2.83], $p$-value=0.09) $($ Table 5). The effect of setting could only be examined in participants of fixed group counselling. We found that fixed group counselling was significantly less effective in a primary care setting (OR:0.15[0.02-1.03], $p$ - value $=0.02)$ and borderline significantly less effective in a community setting (Odds Ratio(OR): 0.07 [0.01-0.64], $p$-value $=0.053$ ) than in a hospital setting (reference category) (Table 6).Within a hospital setting, fixed group had the tendency to be more effective than rolling group counselling (OR fixed group compared to rolling group (reference category): 8.87[0.80-98.84], $p$ value $=0.08)($ Table 7$)$.

\section{DISCUSSION}

The self-reported 12 month continuous abstinence prevalence for the group as a whole was 29.9\%. For the subgroup of participants on which $\mathrm{CO}$-validation was performed, the $\mathrm{CO}$ validated 12 month continuous abstinence prevalence was $6.4 \%$. Using self-reported data, rolling group and individual face-to-face counselling had the highest 12 month continuous abstinence prevalences in disadvantaged areas $(41 \%$ and $34.7 \%$ respectively). CO-validated continuous abstinence prevalences were lower than self-reported prevalences, but the effectiveness of interventions in relationship to one another were preserved. Group counselling, regardless of type, is more effective in a hospital setting.

A strength of this study is that it provides evidence on the effect of various types of SCBT, which has been collected in "real life" settings in disadvantaged areas, rather than effects found in the often non-representative participants and carefully controlled treatment conditions of randomised controlled trials (RCTs) ${ }^{37}$. However, a disadvantage is that it is observational data which in no way mimics an RCT. A disadvantage of not using an RCT design is that the characteristics of the participants in each counselling type might differ as a result of the area characteristics of each service or the self-selection of participants resulting in selection bias. We controlled for this in the analysis, however, it was not a complete control because there was no overlap in some cases (e.g. telephone counselling was only offered in one service). However, we would not recommend an RCT, as the aim was not to find the absolute differences in magnitude of effect between interventions. Also, missing values were retained in the multivariate models so as not to lose sample size. Sensitivity analysis using repeated single imputation gave some altered

Table 4: Self-reported and $\mathrm{CO}$-validated continuous abstinence prevalences, and drop-out at three post-quit date time periods, per counselling type.

\begin{tabular}{|c|c|c|c|c|}
\hline & & Initial $^{* *}$ & 6 months & 12 month \\
\hline \multirow{4}{*}{$\begin{array}{l}\text { Self-reported continuous } \\
\text { abstinence prevalence } \\
(\%)\end{array}$} & All $(n=415)$ & 57.6 & 37.6 & 29.9 \\
\hline & $\begin{array}{l}\text { Individual face-to-face } \\
(n=216)\end{array}$ & 57.9 & 41.2 & 34.7 \\
\hline & Telephone $(n=38)$ & 28.9 & 7.9 & 7.9 \\
\hline & Rolling group $(n=74)$ & 71.1 & 55.4 & 41.0 \\
\hline \multirow{3}{*}{$\begin{array}{l}\text { CO-validated* } \\
\text { continuous abstinence } \\
\text { prevalence }(\%)\end{array}$} & All $(n=109)$ & 37.6 & 8.3 & 6.4 \\
\hline & Telephone $(n=38)$ & 21.1 & 5.3 & 5.3 \\
\hline & Fixed group $(n=71)$ & 45.1 & 9.9 & 7.0 \\
\hline \multirow{3}{*}{$\begin{array}{l}\text { Drop out during follow- } \\
\text { up } n(\%)\end{array}$} & Telephone $(n=38)$ & $14(36.8)$ & $21(55)$ & $25(66)$ \\
\hline & Fixed Group (n=78) & $13(17)$ & $26(33)$ & $29(37)$ \\
\hline & Rolling Group $(n=74)$ & $5(6)$ & $8(10)$ & $10(12)$ \\
\hline
\end{tabular}


results, but did not change the conclusions (results not shown), thus any bias introduced was not worse than missing at random.

A limitation of this study is missing data. In the case of the medical record research, though information on all patients visiting the service between particular dates was available, not all information which we wished to collect was always recorded by both clinics (e.g. highest educational level or Fagerström Test of Nicotine Dependence) ${ }^{38}$. In the case of the survey research, information was missing due to a high percentage of drop-out from the research. Substantial drop-out of participants of low socioeconomic status attending smoking cessation therapy is a known phenomenon ${ }^{36,39}$, and extends to research follow-up as well ${ }^{40}$. Drop-out in this study was highest in telephone counselling, which can have high rates of drop-out after relapse ${ }^{41}$. We do not feel that this drop-out has led to bias in this study, however, because the expectation would be that those who remained would do better than those who dropped out. Missing data were highest in those areas where telephone and fixedgroup counselling were given. The 12 month continuous abstinence prevalences in these areas were already lower than in the other intervention types. One of the variables not available at all sites was motivation to quit. This was generally high for the sites where this data was available (Services A \& B), with average motivation on a 1-10 scale being 8.82 (SD 1.402).

Another limitation of this study is that all four counselling types could only be compared using self-reported rather than $\mathrm{CO}$-validated quit status. Self-report can lead to socially desirable answers in smoking cessation intervention groups ${ }^{42}$. Though in the general population, there is some but not excessive overestimation of the quit prevalence using self-reported data ${ }^{42}$ ${ }^{43}$ we are not aware of any study looking at this specifically for those of low SES. However, we would not expect the results to change if the $\mathrm{CO}$-validation was available for all intervention types for two reasons. Firstly, the quit prevalences recorded by individual face-to-face and rolling group counselling, for which no CO-validation was available, were considerably higher than those reported by telephone counselling and fixed group counselling. While they might decrease with $\mathrm{CO}$-validation, we would not expect them to drop below the levels of fixed group and telephone counselling. Secondly, the relationships found in the self-reported data were preserved in the $\mathrm{CO}$-validated data for the interventions for which data was available.

Use of pharmacotherapy was highest in counselling types provided by clinics where prescriptions were provided to participants, rather than where the participants had to organise their own prescriptions. In all cases the participants had to fill the prescriptions themselves. It is possible that 12 month continuous abstinence prevalences at these clinics are therefore higher than they would otherwise be. However, neither of these clinics had the highest continuous self-reported continuous abstinence prevalence and pharmacotherapy use was controlled for in the analysis.

By comparison with the estimated background smoking cessation prevalence in the general population $(1-4 \%)^{44,45}$, all the intervention types mentioned here had higher continuous abstinence prevalences than the background prevalence of abstinence. However, the magnitude differed greatly, with rolling and individual face-to-face counselling showing much greater abstinence prevalences above the background prevalence than telephone and fixed group counselling. The continuous abstinence prevalences found in this study are also similar or better than those found in SCBT interventions in comparable

Table 5: Multivariate models for predictors of self-reported continuous abstinence at 12 months

\begin{tabular}{|c|c|c|c|c|}
\hline Characteristic & & Model I & $\begin{array}{l}\text { Model } 2 \text { - } \\
\text { including individual characteristics }\end{array}$ & $\begin{array}{l}\text { Model } 3 \text { - } \\
\text { including intervention characteristics }\end{array}$ \\
\hline \multirow[t]{4}{*}{ Counselling type } & $\begin{array}{l}\text { Individual face- } \\
\text { to-face }\end{array}$ & 1.0 & 1.0 & 1.0 \\
\hline & Telephone & $\begin{array}{l}0.16(0.05- \\
0.54)^{*}\end{array}$ & $0.15(0.04-0.52)^{*}$ & $0.18(0.05-0.66)^{*}$ \\
\hline & Rolling group & $1.30(0.78-2.19)$ & $1.57(0.90-2.73)$ & $1.62(0.92-2.83)$ \\
\hline & Fixed group & $0.34(0.17-0.67)^{*}$ & $0.32(0.16-0.66)^{*}$ & $0.31(0.15-0.63)^{*}$ \\
\hline \multirow[t]{4}{*}{ Education } & Low & & 1.0 & 1.0 \\
\hline & Middle & & $1.98(0.94-4.14)$ & $1.93(0.91-4.06)$ \\
\hline & High & & $2.23(1.02-4.89)^{*}$ & $2.15(0.98-4.73)$ \\
\hline & Missing & & $1.05(0.49-2.26)$ & $1.09(0.50-2.36)$ \\
\hline \multirow[t]{3}{*}{ Attendance } & $\leq 3$ & & & 1.0 \\
\hline & $>3$ & & & $1.76(1.04-2.99)^{*}$ \\
\hline & Missing & & & $1.48(0.59-3.71)$ \\
\hline
\end{tabular}


groups elsewhere, ${ }^{13,18,46,47}$.

Rolling group counselling had the highest 12 month continuous abstinence prevalence compared with the other intervention types. This supports the results of Hiscock et al., who found that in most clients, and in particular, in most disadvantaged groups, rolling (open) group counselling gave the highest 4 week quit prevalences ${ }^{18}$. For fixed group counselling the 12 month continuous self-reported abstinence prevalence was lower than either rolling group or individual face-to-face counselling. This differs from Hiscock et al. who found that fixed-group counselling was not significantly different to individual face-toface counselling at four weeks ${ }^{18}$ which was also suggested for the different interventions in the UK services overall ${ }^{13}$. However, when employed in a hospital setting, fixed group counselling appeared to have a similar effect or probably even larger effect than rolling group counselling. Individual face-to-face counselling had a high 12 month self-reported continuous abstinence prevalence, which was similar to that found at 4 weeks in one study ${ }^{18}$ and approximately double the CO-validated prevalence at 12 months found in another study ${ }^{48}$. Telephone counselling had a comparatively low 12 month self-reported and $\mathrm{CO}$-validated continuous abstinence prevalence compared with the other intervention types considered. Also, the highest level of drop-out from the research was experienced in this group. The 12 month self-reported continuous abstinence prevalence in this study was slightly lower than that found in European quitlines in general $(9.4 \%)^{49}$ and similar to that found in a study in a similar disadvantaged target group ${ }^{47}$. The $\mathrm{CO}$-validated prevalence was similar to the self-reported prevalence for this intervention type. If we consider these similar success prevalences, telephone counselling, which is an efficient way to provide individual face-
Table 6: Multivariate model for predictors of self--reported continuous abstinence at 12 months in those whoattending fixed group counselling in various setting types.

$\begin{array}{lll}\text { Characteristic } & & \text { Vlodel } \\ \text { Education* } & \text { Low } & 1.0 \\ & \text { Middle } & 0.93(0.17-5.15) \\ \text { High } & 1.82(0.28-11.80) \\ \text { Attendance } & \leq 3 & 1.0 \\ & >3 & 0.28(0.03-2.75) \\ \text { Service setting } & \text { Missing } & 0.17(0.01-2.84) \\ & \text { Hospital } & 1.0 \\ & \text { Primary care } & 0.07(0.01-0.64)^{* *} \\ & \text { Community } & 0.15(0.02-1.03)^{* * *}\end{array}$

*The missing category was removed for this calculation because it contained only one participant. ${ }^{* *} p<0.05{ }^{* * *} p=0.053$

to-face counselling to large numbers of the citation after, people ${ }^{9}$ may also hold potential for widespread promotion and use in disadvantaged areas in the Netherlands. However, as better results were obtained in other intervention types in this study, we would recommend focussing on these first.

Both clinics in hospital settings were also specialist smoking cessation services. Specialist clinics have been found to be more effective than other service settings in the $\mathrm{UK}^{17}$. It is possible that the specialist nature of the clinics contributed to the results found here. However, given the large differences in the physical locations of the clinics, we are cautious to make this link. Entering a hospital for SCBT, where patients and medical staff are a visible reminder of possible future consequences of continued smoking, may have a very different effect on a smoker considering quitting,

\section{Figure 1: Participants and Counselling Type}

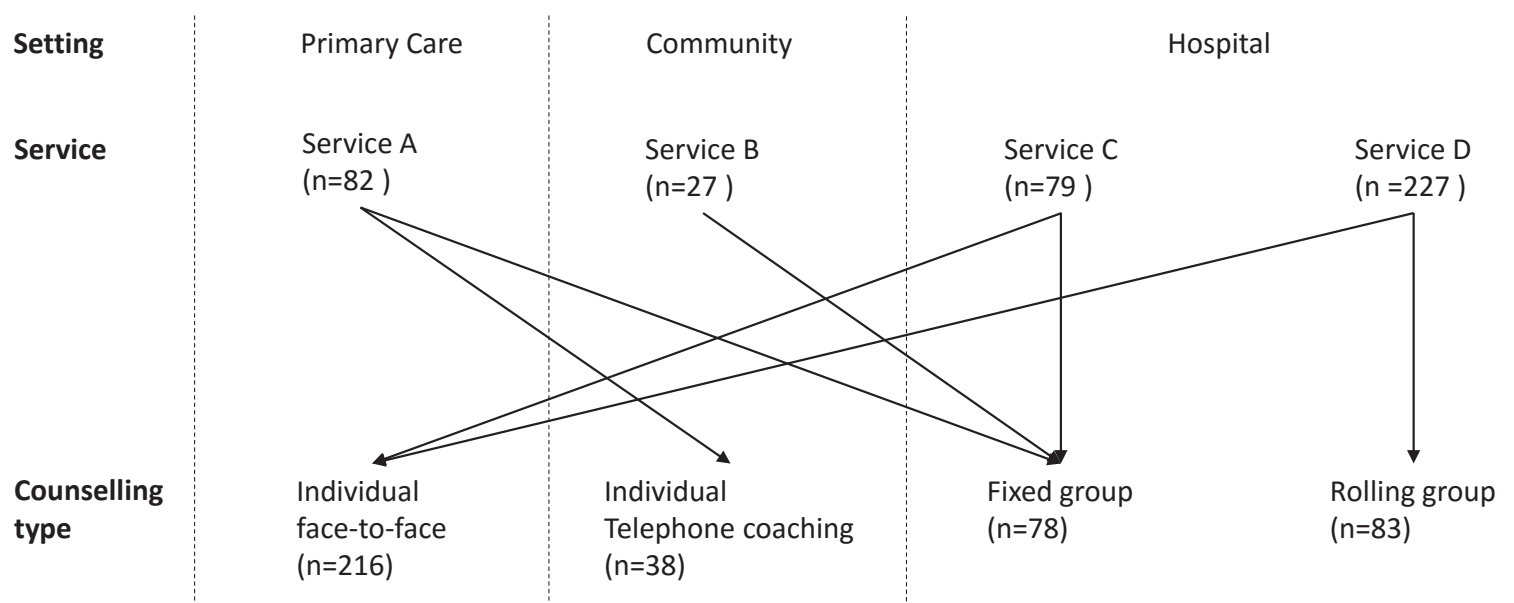




\begin{tabular}{|c|c|c|c|c|}
\hline Characteristic & & $\begin{array}{l}\text { Model } 1 \text { - } \\
\text { univariate model }\end{array}$ & $\begin{array}{l}\text { Model } 2 \text { - } \\
\text { including individual characteristics }\end{array}$ & $\begin{array}{l}\text { Model } 3 \text { - } \\
\text { including intervention characteristics }\end{array}$ \\
\hline \multirow[t]{2}{*}{ Counselling type } & Rolling group & 1.0 & 1.0 & 1.0 \\
\hline & Fixed group & $1.92(0.40-9.14)$ & $8.39(0.79-89.39)$ & $8.87(0.80-98.84)$ \\
\hline \multirow[t]{4}{*}{ Education } & Low & & 1.0 & 1.0 \\
\hline & Middle & & $1.93(0.24-15.67)$ & $2.05(0.25-16.79)$ \\
\hline & High & & $0.23(0.01-3.75)$ & $0.25(0.02-4.14)$ \\
\hline & Missing & & $2.57(0.36-18.14)$ & $2.51(0.35-17.97)$ \\
\hline \multirow[t]{3}{*}{ Attendance } & $\leq 3$ & & & 1.0 \\
\hline & $>3$ & & & $0.69(0.26-1.82)$ \\
\hline & Missing & & & $1.25(0.21-7.30)$ \\
\hline
\end{tabular}

compared to entering a community centre or GP surgery, where many people are not visibly seriously ill. Hospitalization is known to be a 'teachable moment' for smoking cessation in patients ${ }^{50}$ and perhaps it could also work this way for smokers motivated enough to enter the hospital for SCBT.

We targeted smokers in disadvantaged areas. However, not all participants were of low educational level. Area disadvantage predicts higher smoking prevalence and lower quit success independently of other SES measures, such as education and income ${ }^{2,6}$. However, if the aim of a study is specifically to recruit smokers with individual-level low SES characteristics, in addition to being from disadvantaged areas, then further measures must be taken to target those groups.

These results, which, as discussed previously, partially support those found in the UK, are generalisable to other disadvantaged areas in the Netherlands because of the representation of different types of disadvantaged areas, for example with respect to the proportion of ethnic minority residents. Also, while not all counselling types were available in all areas, some were available in most (fixed group counselling) or half (individual face-to-face counselling) the areas. While the magnitude of the results may not be directly generalizable to other countries, it is possible that the finding that rolling group counselling is very effective at 12 months in disadvantaged areas, and that hospital setting may be influential, is generalizable to other high income countries.

These findings have implications for smoking cessation practice in disadvantaged areas. Group and individual face-toface counselling offered in a hospital setting are more effective than fixed group and telephone counselling offered in a primary care and community setting respectively. Because in group counselling a greater number of smokers are seen by the therapist in the same amount of time than in individual face-to- face therapy ${ }^{51}$ the population impact of smoking cessation services in disadvantaged areas is likely to be larger if they focus more on group therapy, and, if possible, in hospital settings. This is as long as uptake is adequate ${ }^{8}$.

We would also recommend the development of a standard for data registered by smoking cessation services across the Netherlands, as is the case in the $\mathrm{UK}^{52}$. This should include recommendations for follow-up of participants in terms of techniques used (for example, using CO-validation on a sample of participants) and minimum targets (e.g. in the UK the recommendation is $\mathrm{CO}$-validation of $85 \%$ of patients at 4 weeks $)^{52}$. This would aid services in their quality assurance procedures by enabling direct comparison between clinics, and, would at the same time, aid research in this area.

\section{CONCLUSION}

Smoking cessation behavioural therapy provided in a group format in a hospital setting is the most successful intervention type in disadvantaged areas in the Netherlands. Individual counselling provided in a hospital setting is also very effective. However, given the higher number of smokers which can be treated in the same time period using group therapy in comparison with individual therapy, we recommend that services in disadvantaged areas concentrate on offering group therapy and do so in a hospital setting, where possible.

\section{REFERENCES}

1. Tobacco Free Initiative (TFI): Tobacco Facts. Available at: http:// www.who.int/tobacco/mpower/tobacco_facts/en/ (accessed 16 July 2015)

2. Shohaimi S, Luben R, Wareham N, Day N, Bingham S, Welch A, Oakes S, Khaw KT: Residential area deprivation predicts smoking habit independently of individual educational level and occupational social class. A cross sectional study in the Norfolk cohort of the European Investigation into Cancer (EPIC-Norfolk). J Epidemiol 
Community Health 2003, 57(4):270-276. doi: 10.1136/jech.57.4.270

3. Pearce J, Barnett R, Moon G: Sociospatial inequalities in healthrelated behaviours: Pathways linking place and smoking. Prog Hum Geog 2012, 36(1):3-24. doi: 10.1177/0309132511402710

4. Pickett KE, Pearl M: Multilevel analyses of neighbourhood socioeconomic context and health outcomes: a critical review. J Epidemiol Community Health 2001, 55(2):111-122. doi:10.1136/jech.55.2.111

5. Giskes K, van Lenthe FJ, Turrell G, Brug J, Mackenbach JP: Smokers living in deprived areas are less likely to quit: a longitudinal follow-up. Tob Control 2006, 15(6):485-488. doi: $10.1136 /$ tc.2006.015750

6. Businelle MS, Kendzor DE, Reitzel LR, Costello TJ, Cofta-Woerpel L, Li YS, Mazas CA, Vidrine J, Cinciripini PM, Greisinger AJ et al: Mechanisms Linking Socioeconomic Status to Smoking Cessation: A Structural Equation Modeling Approach. Health Psychol 2010, 29(3):262-273.

doi: $10.1037 / \mathrm{a} 0019285$

7. Stead LF, Lancaster T: Combined pharmacotherapy and behavioural interventions for smoking cessation. Cochrane Database Syst Rev 2012, 10:CD008286.

doi: 10.1002/14651858.CD008286.pub2

8. Stead LF, Lancaster T: Group behaviour therapy programmes for smoking cessation. Cochrane Database Syst Rev 2005(2): CD001007.

9. Stead LF, Hartmann-Boyce J, Perera R, Lancaster T: Telephone counselling for smoking cessation. Cochrane Database Syst Rev 2013, 8:CD002850. doi: 10.1002/14651858.CD002850.pub3

10. LancasterT, Stead LF: Individual behavioural counselling for smoking cessation. Cochrane Database Syst Rev 2005(2):CD001292.

11. Benson FE, Stronks K, Willemsen MC, Bogaerts NM, Nierkens V: Wanting to attend isn't just wanting to quit: why some disadvantaged smokers regularly attend smoking cessation behavioural therapy while others do not: a qualitative study. BMC Public Health 2014, 14:695.

doi: 10.1186/1471-2458-14-695.

12. de Weert B: Pakje Kans. Samen stoppen met roken handbook. Den Haag: STIVORO voor een rookvrije toekomst.; 2009.

13. Bauld L, Ferguson J, McEwen A, Hiscock R: Evaluation of a drop-in rolling-group model of support to stop smoking. Addiction 2012, 107(9):1687-1695. doi: 10.1111/j.1360-0443.2012.03861.x

14. van Ernst A, M W: Telefonische Coaching bij Stoppen met Roken. Handleiding voor de coach. Utrecht: STIVORO; 2008.

15. World Health Organisation (WHO): Developing and improving national toll-free tobacco quit line services. A World Health Organizaton manual. In., November 2011 edn. France: World Health Organisation (WHO); 2011.

16. Bauld L, Bell K, McCullough L, Richardson L, Greaves L: The effectiveness of NHS smoking cessation services: a systematic review. J Public Health (Oxf) 2010, 32(1):71-82. doi: 10.1093/pubmed/fdp074.

17. Brose LS, West R, McDermott MS, Fidler JA, Croghan E, McEwen A: What makes for an effective stop-smoking service? Thorax 2011, 66(10):924-926. doi: 10.1136/thoraxjnl-2011-200251

18. Hiscock R, Murray S, Brose LS, McEwen A, Bee J, Dobbie F,
Bauld L: Behavioural therapy for smoking cessation: the effectiveness of different intervention types for disadvantaged and affluent smokers. Addict Behav 2013, 38(11):2787-2796.

doi: 10.1016/j.addbeh.2013.07.010

19. Hiscock R, Moon G, Pearce J, Barnett R, Daley V: Do general medical practice characteristics influence the effectiveness of smoking cessation programs? A multilevel analysis. Nicotine Tob Res 2012, 14(6):703-710. doi: $10.1093 / \mathrm{ntr} / \mathrm{ntr} 271$

20. Judge K, Bauld L, Chesterman J, Ferguson J: The English smoking treatment services: short-term outcomes. Addiction 2005, $100 \mathrm{Suppl}$ 2:46-58.

21. Bauld L, Boyd KA, Briggs AH, Chesterman J, Ferguson J, Judge $\mathrm{K}$, Hiscock R: One-year outcomes and a cost-effectiveness analysis for smokers accessing group-based and pharmacy-led cessation services. Nicotine Tob Res 2011, 13(2):135-145.

doi: $10.1093 / \mathrm{ntr} / \mathrm{ntq} 222$

22. Khara M, Okoli C, Nagarajan VD, Aziz F, Hanley C: Smoking cessation outcomes of referral to a specialist hospital outpatient clinic. Am J Addict 2015, 24(6):561-570. doi: 10.1111/ajad.12259

23. Kwaliteitsregister Stoppen met Roken: Goedgekeurde (geaccrediteerde) interventies. Available at: www.kwaliteitsr egisterstopmetroken.nl/geaccrediteerde-activiteiten/interventies/

24. Wittebrood K, Permentier, M.,: Wonen, wijken \& interventies. Krachtwijkenbeleid in perspectief. In. Edited by Planbureau SeC. Den Haag: Sociaal en Cultureel Planbureau; 2011.

25. Benson FE, Nierkens V, Willemsen MC, Stronks K. Smoking cessation behavioural therapy in disadvantaged neighbourhoods: an explorative analysis of recruitment channels. Subst Abuse Treat Prev Policy 2015, 10:28. doi: 10.1186/s13011-015-0024-3

26. Kwaliteitsregister Stoppen met Roken: Zoek een stoppen-metrokenbegeleider Available at: http://www.kwaliteitsregisterstopmet roken.nl/zoeken/?pagina=7\& (accessed 16 July 2015)

27. Dekker P, de Kanta W: Nederland Stopt! Met Roken. Nederland: Thoeris; 2008.

28. Dekker P, de Kanta W: Nederland stopt! Met roken. (Luisterboek). In. Nederland: Theoris; 2011.

29. Help-me-on-my-way! Available at: http://www.ccmo.nl/en/helpme-on-my-way (accessed 16 July 2015)

30. Mackenbach JP: Socio-economic health differences in The Netherlands: a review of recent empirical findings. Soc Sci Med 1992, 34(3):213-226.

31. Kandel DB, Chen K. Extent of smoking and nicotine dependence in the United States: 1991-1993. Nicotine Tob Res 2000, 2(3):263274.

32. West R, Hajek P, Stead L, Stapleton J: Outcome criteria in smoking cessation trials: proposal for a common standard. Addiction 2005, 100(3):299-303.

33. Partnership Stop met Roken: Richtlijn Behandeling van Tabaksverslaving Herziening 2009. In. Den Haag: Partnership Stop met Roken; 2009.

34. Weinberger AH, Pittman B, Mazure CM, McKee SA: A behavioral smoking treatment based on perceived risks of quitting: A preliminary feasibility and acceptability study with female smokers. Addiction research \& theory 2015, 23(2):108-114. doi: 10.3109/16066359.2014.933813

35. Vangeli E, Stapleton J, Smit ES, Borland R, West R: Predictors of attempts to stop smoking and their success in adult general 
population samples: a systematic review. Addiction 2011, 106(12):2110-2121. doi: 10.1111/j.1360-0443.2011.03565.x

36. Hiscock R, Judge K, Bauld L: Social inequalities in quitting smoking: what factors mediate the relationship between socioeconomic position and smoking cessation? J Public Health (Oxf) 2011, 33(1):39-47. doi: 10.1093/pubmed/fdq097

37. Rothwell PM: External validity of randomised controlled trials: "to whom do the results of this trial apply?". Lancet 2005, 365(9453):82-93. doi:10.1016/S0140-6736(04)17670-8

38. Heatherton TF, Kozlowski LT, Frecker RC, Fagerstrom KO: The Fagerstrom Test for Nicotine Dependence: a revision of the Fagerstrom Tolerance Questionnaire. Br J Addict 1991, 86(9):11191127.

39. Hiscock R, Bauld L, Amos A, Fidler JA, Munafo M: Socioeconomic status and smoking: a review. Ann N Y Acad Sci 2012, 1248:107123.

40. Leeman RF, Quiles ZN, Molinelli LA, Terwal DM, Nordstrom BL, Garvey AJ, Kinnunen T: Attrition in a multi-component smoking cessation study for females. Tob Induc Dis 2005, 3(1):59-71. doi: 10.1186/1617-9625-3-2-59

41. Rabius V, Pike KJ, Hunter J, Wiatrek D, McAlister AL: Effects of frequency and duration in telephone counselling for smoking cessation. Tob Control 2007, 16 Suppl 1:i71-74.

42. Murray RP, Connett JE, Istvan JA, Nides MA, Rempel-Rossum S: Relations of cotinine and carbon monoxide to self-reported smoking in a cohort of smokers and ex-smokers followed over 5 years. Nicotine Tob Res 2002, 4(3):287-294.

doi: 10.1080/14622200210141266

43. Patrick DL, Cheadle A, Thompson DC, Diehr P, Koepsell T, Kinne S: The validity of self-reported smoking: a review and meta-analysis. Am J Public Health 1994, 84(7):1086-1093.

44. Zhu SH, Lee M, Zhuang YL, Gamst A, Wolfson T: Interventions to increase smoking cessation at the population level: how much progress has been made in the last two decades? Tob Control 2012, 21(2):110-118.

doi: 10.1136/tobaccocontrol-2011-050371.

45. Background smoking cessation rates in England. Available at: http://www. smokinginengland.info/Ref/paper2.pdf (accessed 16 July 2015)

46. West R, May S, West M, Croghan E, McEwen A: Performance of English stop smoking services in first 10 years: analysis of service monitoring data. BMJ 2013, 347:f4921.

doi: 10.1136/bmj.f4921.

47. Zhu SH, Anderson CM, Tedeschi GJ, Rosbrook B, Johnson CE, Byrd M, Gutierrez-Terrell E: Evidence of real-world effectiveness of a telephone quitline for smokers. N Engl J Med 2002, 347(14):10871093. doi: 10.1056/NEJMsa020660

48. Ferguson J, Bauld L, Chesterman J, Judge K: The English smoking treatment services: one-year outcomes. Addiction 2005, 100 Suppl 2:59-69. doi: 10.1111/j.1360-0443.2005.01028.x

49. Willemsen MC, van der Meer RM, Bot S: Description, effectiveness, and client satisfaction of 9 European Quitlines: Results of the European Smoking Cessation Helplines Evaluation Project (ESCHER). In. Den Haag: STIVORO for a smoke free future; 2008.

50. McBride CM, Emmons KM, Lipkus IM: Understanding the potential of teachable moments: the case of smoking cessation. Health Educ
Res 2003, 18(2):156-170.

doi: $10.1093 /$ her/18.2.156

51. Becona E, Miguez M: Group Behaviour Therapy for Smoking Cessation. Journal of Groups in Addiction \& Recovery 2008, 3(12):63-78. doi: 10.1002/14651858.CD001007.pub2

52. Croghan E: Local Stop Smoking Services: Service Delivery and Monitoring Guidance 2011/12. In. Edited by Health Do. United Kingdom: Department of Health; 2011.
ACKNOWLEDGEMENTS

The authors would like to thank Pauline Haasbroek, Roos Blom and Tiny Rooijendijk, for their kind assistance in providing (access to) data.

CONFLICT OF INTEREST The authors have completed and submitted the ICMUE Form for Disclosure of Potential Conflicts of Interest and none were reported.

FUNDING

This work was supported by The Netherlands Organisation for Health Research and Development (ZonMw) (Project number: 200120004).

AUTHOR CONTRIBUTIONS

All authors conceived the study. All authors designed the study. FB prepared and analysed the data. All authors contributed to the interpretation of the data. FB drafted the article. All authors contributed to critical revision of the manuscript. All authors approved the final version of the manuscript.

PROVENANCE AND PEER REVIEW

Not commissioned; externally peer reviewed 